\title{
The Research on the Analysis and Application of Detecting Underground Civil Air Defense with GPR
}

\author{
Yongqing Yang1 ${ }^{*}$, Xiaohui Sun ${ }^{2}$ \\ ${ }^{1}$ College of Civil and Transportation Engineering, Hohai University, Nanjing, China \\ ${ }^{2}$ College of Construction Engineering, Qingdao Huanghai University, Qingdao, China \\ Email: ${ }^{*}$ yq yang2002@hhu.edu.cn
}

Received 4 July 2015; accepted 15 October 2015; published 22 October 2015

\begin{abstract}
On the basis of the principle of Ground Penetrating Radar (GPR) method and geophysical characteristics, this paper discusses in detail detection method of civil air defense distinguished by GPR under the complex geological condition through using the analysis and application in the survey of underground civil air defense as an example. Three dimensional image of the defense clearly reflects its underground structure. Test result has the greatly high detection precision. This example illustrates the effectiveness and practicability of GPR in the respect of detection of the civil air defense and also accumulates experiences for the application of GPR in urban geological survey.
\end{abstract}

\section{Keywords}

GPR, Civil Air Defense, Complex Geological Condition, Three Dimensional Image

\section{Introduction}

Ground penetrating radar (GPR) is a highly efficient shallow geophysical detection technology. By transmitting high-frequency electromagnetic pulse wave, GPR method uses the difference of the electrical parameters of underground medium according to the kinematics and dynamics characteristics such as the amplitude, waveform and frequency of the echo to analyze and infer the medium structure and physical characteristics [1]-[7]. Comparing with the traditional geophysical methods, because of the prominent advantages of nondestructive, fast, simple and high precise, GPR leads to wide attention in engineering geophysical exploration. GPR instrument system can be divided into time domain and frequency domain system. Time domain GPR system is widely used in engineering investigation. Its main advantage is radar image can intuitively reflect the structure of underground medium in field measurement. Frequency domain GPR system is mainly acquiring electromagnetic wave frequency domain response of the medium by using Fourier transformation. Stepped frequency GPR system requires complex hardware system and signal processing technology [8]-[10], thus its development is slow, but it has better resolution and accuracy. Now GPR is applied in many fields such as geology, engineering, re-

${ }^{*}$ Corresponding author.

How to cite this paper: Yang, Y.Q. and Sun, X.H. (2015) The Research on the Analysis and Application of Detecting Underground Civil Air Defense with GPR. World Journal of Engineering and Technology, 3, 52-58. 
source, environment, military and so on [11]-[13]. The working frequency band is normally reached $10 \mathrm{MHz}-3$ GHz. It can meet the requirements of a large number of engineering and exploration.

Urban underground civil air defense engineering brings great harm to surface structures and metro construction. The events of the building deformation and collapse have often occurred owing to the defense. Therefore, it is very important to find out the distribution of underground civil air defense project and ensure building quality and safety before architecture design and construction. General surveying methods of the defense are by using drilling and geophysical methods. For the defense buried in shallow, GPR detection is effective. Due to the area of the defense is often located in the demolition and relocation sites or below the asphalt concrete pavement, the medium condition is bad, so the effects of shallow medium inhomogeneity should be eliminated during the data processing [14]-[16]. For the objectionable exceptions, we should also take other geophysical methods or drilling or direct excavation.

\section{Materials and Methods}

\subsection{Study Area}

An experimental zone was built at asphalt pavement which was located in Zhongshan west road owned by Ningbo city (China). The range of the experimental zone was from Haishu branch of agriculture bank of China to the oral cavity hospital and in the south of Zhongshan west road. Three survey lines were set along the road. Survey direction was from drive lane to sidewalk. Line spacing was 100 meters. The detailed survey line layout was shown in Figure 1.

\subsection{GPR Principle}

Underground interface or spatial location of hazardous mass, underground structure, dielectric constant of medium etc can be determined by processing and analysis of time domain waveform. Radar image is often shown in the form of pulse reflection waveform record. The positive and negative peaks of the waveform are respectively expressed as black and white, or gray or pseudo color. Equal gray or isochromate reflection event can be used to express underground interface.

\subsection{Data Acquisition}

Low and medium frequency antenna should be adopted for defense detection. In the case of defense to known, survey line arrangement should be perpendicular to the civil air defense. To collect data in GPR field surveying, a SIR-10H system from GSSI company was used. Accordingly, 400-MHz and $100-\mathrm{MHz}$ antennas were used for data acquisition. Penetrating depth were $3.0 \mathrm{~m}$ and $6.0 \mathrm{~m}$ respectively. Considering an average radar-wave velocity of $13.4 \mathrm{~cm} / \mathrm{ns}$ (dielectric permittivity $\varepsilon \mathrm{r}=5$ ), as reported in the literature for asphalt medium [10]. The GPR data was acquired using the distance-mode. For 400-MHz antenna, samples per scan, scans per meter, and time window range were set at 512, 50, 60 ns. But for 100-MHz antenna, these parameters were set 512, 50, 120 ns. So GPR scans were obtained at six profiles in the study area.

\subsection{Data Processing}

The data collected is processed with Radan 2.0 software in order to correct the down-shifting of the radar section

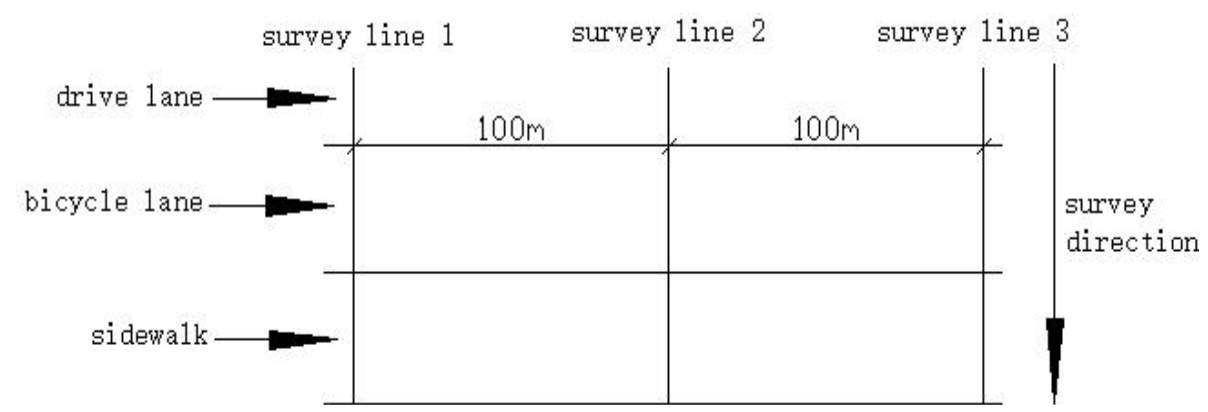

Figure 1. Layout drawing of observing system. 
due to the air-ground interface and to remove both low and high-frequency noise in the vertical and horizontal directions, as well as to amplify the received signal. The processing sequence applied is: time-zero correction, dewow filtering, gain application ("gain function” with linear and exponential components), spatial filtering ("background removal”), and band-pass ("butterworth") filter. GPR data processing objective is to suppress random and rule interference. GPR image shows available reflection with the greatest possible resolution. Extraction of reflected wave's useful parameters (e.g. electromagnetic wave velocity, amplitude and waveform) is helpful to explain.

\section{Results and Discussions}

The measurement data of every survey line processed were shown in the following GPR profiles (Figures 2-7). Most reflections on the asphalt concrete pavement gave the velocity of $13.4 \mathrm{~cm}$ per nanosecond which corresponded to the material dielectric constant $\varepsilon_{r}=5$.

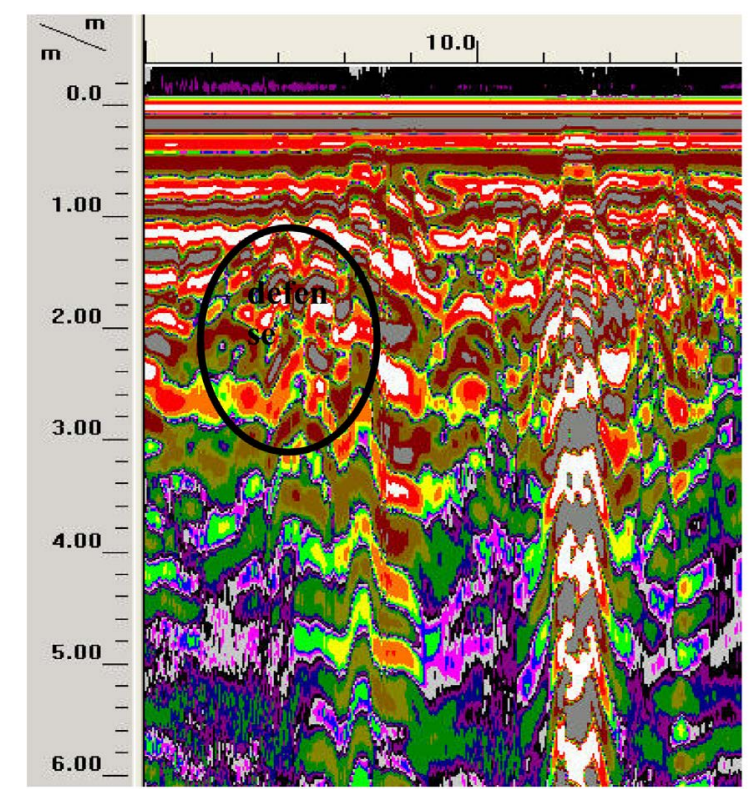

Figure 2. GPR image of survey line 1 (100 MHz).

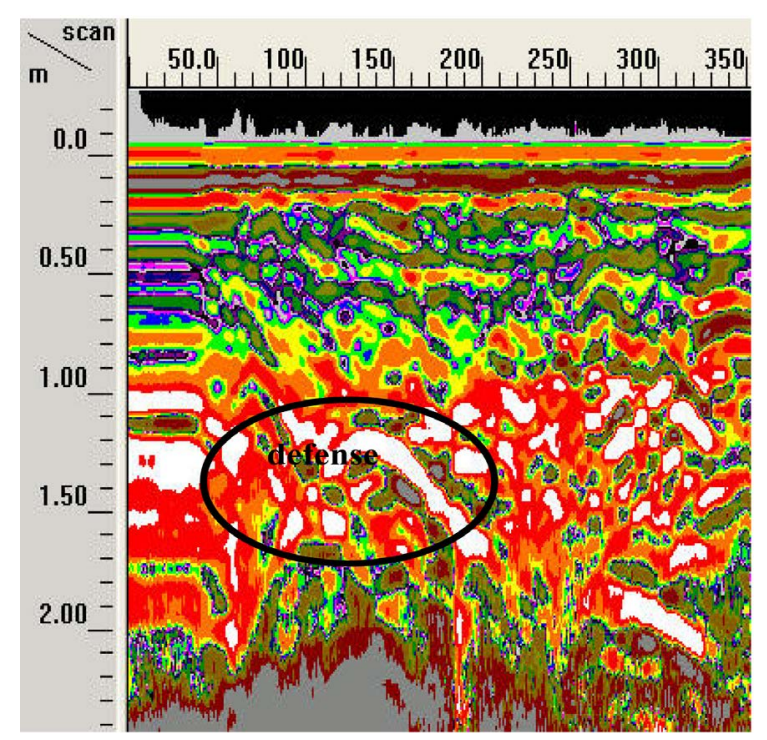

Figure 3. GPR image of survey line 1 (400 MHz). 


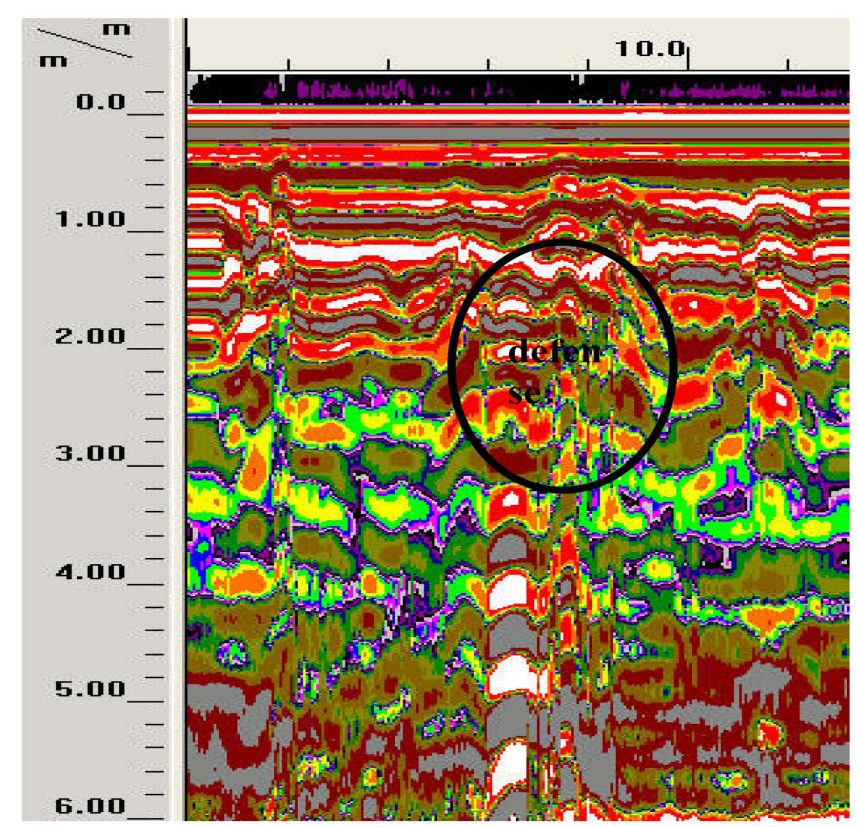

Figure 4. GPR image of survey line 2 (100 MHz).

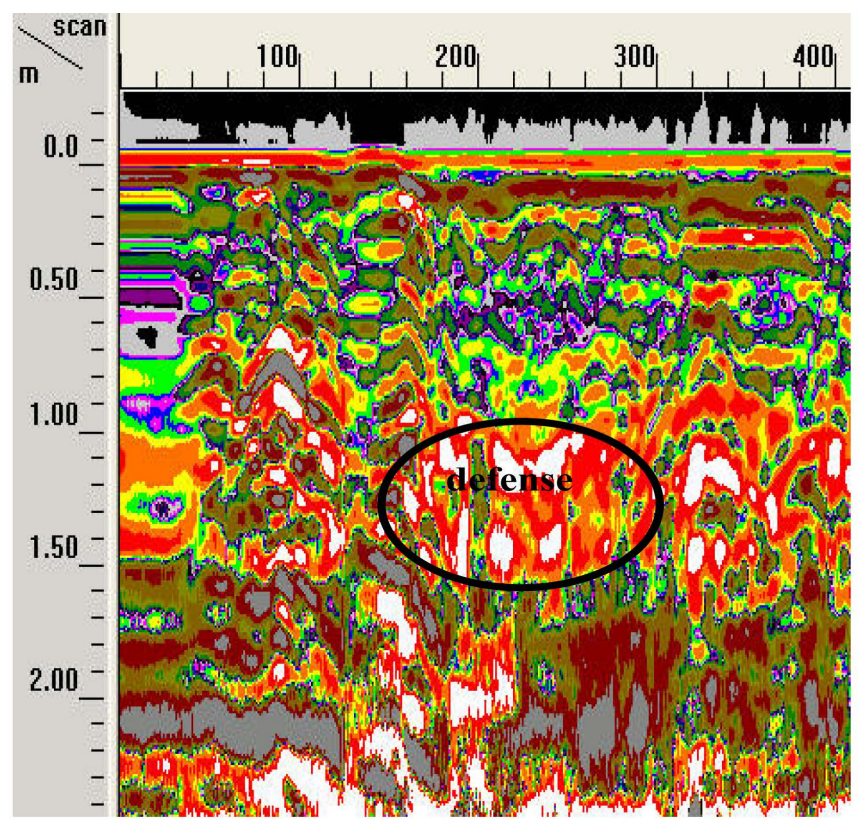

Figure 5. GPR image of survey line 2 (400 MHz).

Since the road was located in the downtown area, the distribution of underground pipeline was particularly intense, radar reflection of pipeline would also affect the detection effect of the civil air defense, so the detection had the certain difficulty. Firstly, GPR was used to detect the defense. After the data processing such as filtering, all the anomalies including pipeline and defense were found out. Combined with the location of the surface pipeline, we could make a preliminary screening. Finally, we found the most likely location from the rest of the anomalies and excavated the sites. Compared with the radar detection results and excavation results, we could determine the surface position and depth of the civil air defense.

The above GPR images of the three survey lines showed that the detection accuracy of $400 \mathrm{MHz}$ antenna was higher than $100 \mathrm{MHz}$ antenna. What's more, the defense depth was more than 2 meters, the measuring effect of 


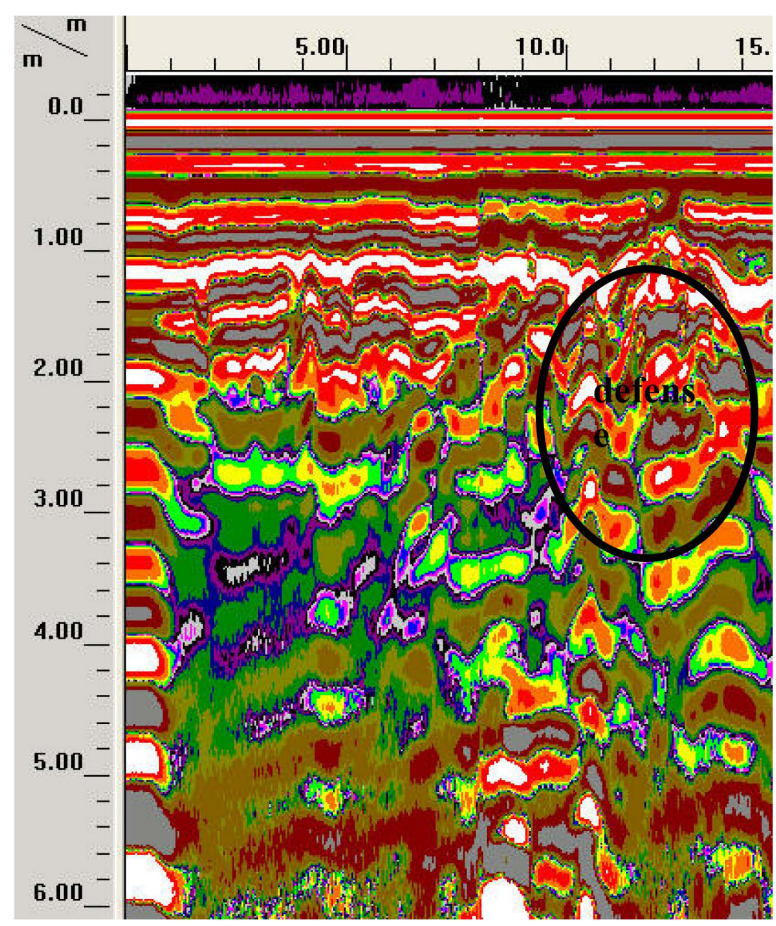

Figure 6. GPR image of survey line 3 (100 MHz).

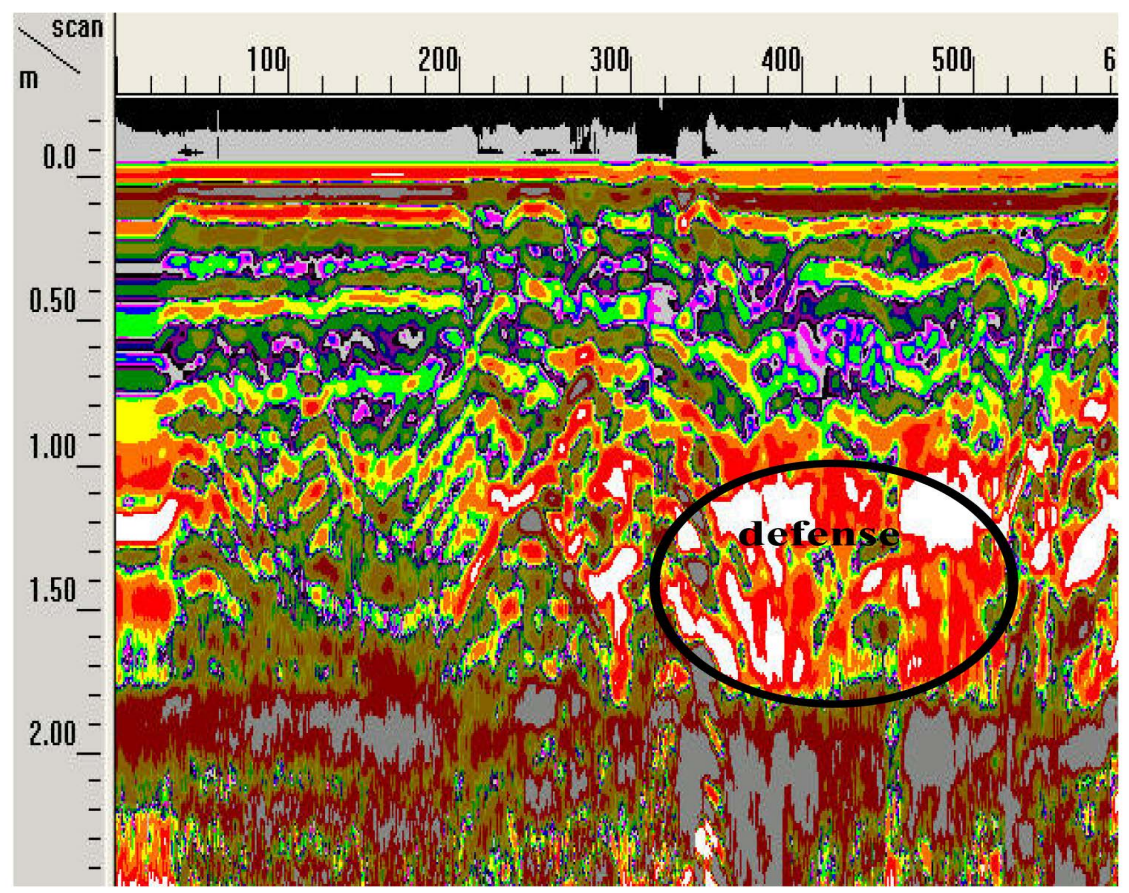

Figure 7. GPR image of survey line 3 (400 MHz).

$400 \mathrm{MHz}$ antenna was better than $100 \mathrm{MHz}$ antenna. The civil air defense was easy to identify from the GPR images of $400 \mathrm{MHz}$ antenna. But the radar image of $100 \mathrm{MHz}$ antenna could display the bottom of the defense and the $400 \mathrm{MHz}$ image could not show it. The $400 \mathrm{MHz}$ image could only display the reflection of the top defense. The black oval circle of each image represented the position of the civil air defense. The surface position of the civil air defense was shown in Figure 8. 
After the measurement was finished by using $100 \mathrm{MHz}$ antenna, the position of civil air defense was determined by the results detected. However, the abnormal detected by $400 \mathrm{MHz}$ antenna was found, we immediately sprayed on the ground. The abscissa was the moving distance for $100 \mathrm{MHz}$ antenna and the scans for $400 \mathrm{MHz}$ antenna respectively. Although the abscissa was different in GPR image and the starting point location of the survey line was also different, the surface point location was consistent with the corresponding civil air defense. During the field measurement, the corresponding tags were made on the surface. Through the attachment of various civil air defense points, we could determine the defense strike (Figure 8).

The buried depth of the defense top was 1.1 meters under the ground and the width was about 2 meters. The actual position was located in the intersection between non-motor lane and pavements. Meanwhile, the position was the side near the sidewalk.

As the sketch of the defense was two dimensional (2D) map, it could not intuitively reflect the spatial location of the civil air defense. Thus to intuitively see the position and shape of the defense, it needed to have a three dimensional (3D) display (Figure 9). X-axis was survey-direction, $\mathrm{y}$-axis was the extension-direction of the defense, and z-axis was the depth.

\section{Conclusions}

The GPR detection results could truly reflect the position of the underground civil air defense according to the above analysis and the excavation. The detection results had a very high accuracy and were suitable for the urban geological survey. Therefore, it had a reference role for underground engineering construction. It also proved that the GPR detection of shallow underground civil air defense was an effective method. It would play a

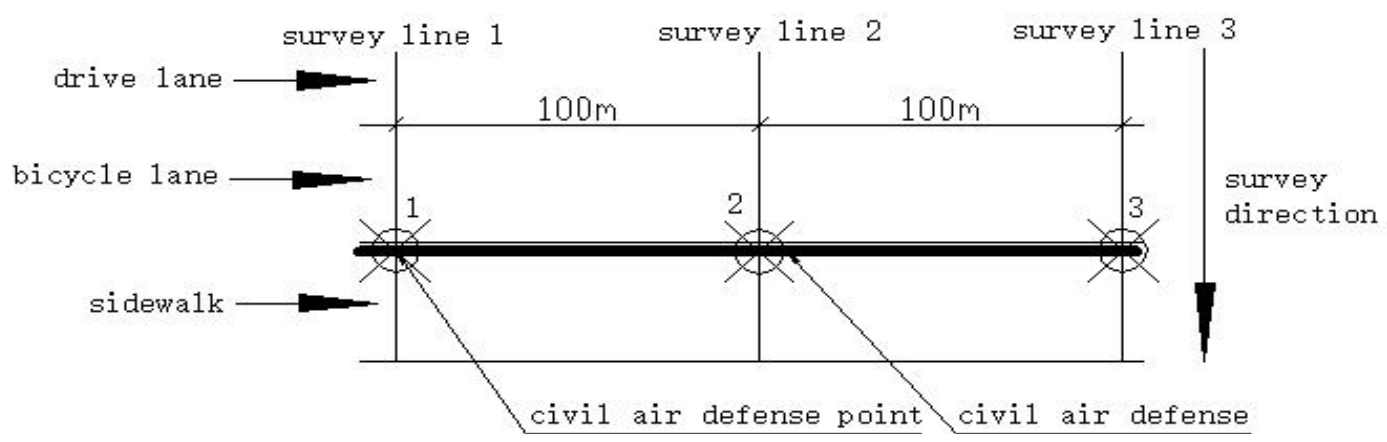

Figure 8. Civil air defense sketch on the ground.

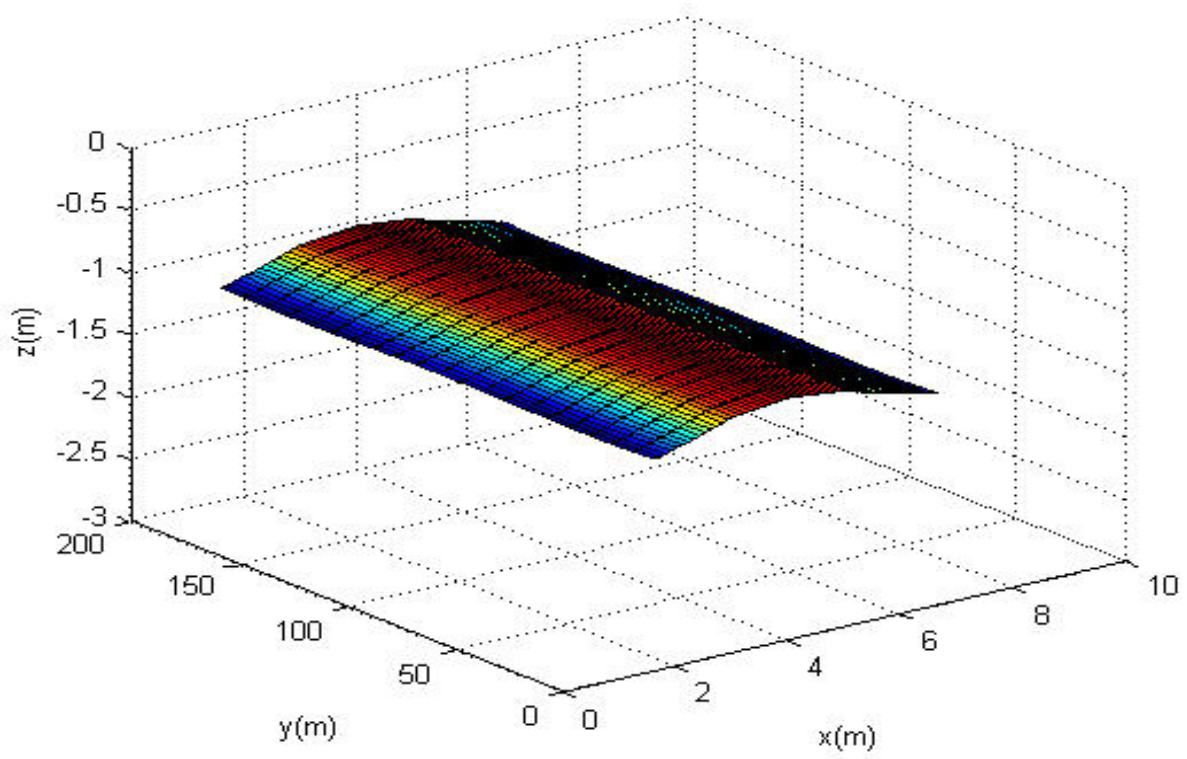

Figure 9. 3D image of civil air defense top. 
more and more important role in the urban geological survey. However, GPR detection technology was also developing step by step, compared with other geophysical methods, its accuracy rate was not likely to reach one hundred percent. Some problems needed to pay attention.

1) Before measurement, we needed to know the landform and geological conditions of test area, set up the appropriate measurement parameters in order to achieve the most precise data.

2) It was very important to identify all kinds of interference correctly. The analysis of measurement results was accurate.

3) How to carry out the accurate judgment from all abnormal situation that appeared on the GPR images, it needed a lot of experience. At the same time, it also needed to combine with other geological data and the results of drilling or digging and make a compositive explanation.

\section{Acknowledgements}

This research was funded by the Natural Science Foundation of China (51308192) and basic scientific research business expenses of the central university of Hohai university (2010B04114). We expressed our gratitude to harbor laboratory provided GSSI radar system. We kindly thanked Hui Cai and Li Yuan for the fieldwork operations and the GPR data acquisition.

\section{References}

[1] David, L.M. and Puskars, R.J. (1967) A Subsurface Electromagnetic Pulse Radar. Geophysics, 41, 506-518.

[2] Bohidar, R.N. and Hermance, J.F. (2002) The GPR Refraction Method. Geophysics, 67, 1474-1485. http://dx.doi.org/10.1190/1.1512792

[3] Neal, A. (2004) Ground Penetrating Radar and Its Use in Sedimentology: Principle, Problem and Progress. Earth Science Reviews, 66, 261-330. http://dx.doi.org/10.1016/j.earscirev.2004.01.004

[4] Li, D.X. (1994) Ground Penetrating Radar (GPR) Method and Application. Geology Publishing House, Beijing.

[5] Al-Qadi, I.L., Leng, Z. and Larkin, A. (2011) In-place Hot Mix Asphalt Density Estimation Using Ground Penetrating Radar. Ph.D. Thesis, University of Illinois, Urbana, Illinois.

[6] Wang, M. (2007) Research on Influencing Factors of GPR’s Detection Effectiveness. Radar Science and Technology, 2, 86-90.

[7] Lei, L.Y. (1998) Some Basic Problems in the Application of Ground-Penetration Radar. Geophysical \& Geochemical Exploration, 6, 408-414.

[8] Kong, F.-N. and By, T.L. (1995) Performance of a GPR System Which Uses Step Frequency Signals. Journal of Applied Geophysics, 33, 15-26. http://dx.doi.org/10.1016/0926-9851(95)90026-8

[9] Stickley, G.F., Noon, D.A., Cherniakov, M. and Longstaff, I.D. (2000) Gated Stepped-Frequency Ground Penetrating Radar. Journal of Applied Geophysics, 43, 259-269. http://dx.doi.org/10.1016/S0926-9851(99)00063-4

[10] Zeng, Z.F., Liu, S.X., Wang, Z.J. and Xie, J. (2006) The Method Principle and Application of Ground Penetrating Radar. Science Publishing House, Beijing.

[11] Zhou, L.J., Dong, R.W., Xu, B. and Yang, Y.Q. (2009) The Application of Ground Penetrating Radar in City Geological Investigation. Chinese Journal of Engineering Geophysics, 6, 632-635.

[12] Liu, L.B. and Arcone, S.A. (2013) Forward and Inverse Problems in GPR Research. Journal of Applied Geophysics, 99, 66-67. http://dx.doi.org/10.1016/j.jappgeo.2013.08.012

[13] Zajc, M., Pogaěnik, Ž. and Gosar, A. (2014) Ground Penetrating Radar and Structural Geological Mapping Investigation of Karst and Tectonic Features in Flyschoid Rocks as Geological Hazard for Exploitation. International Journal of Rock Mechanics \& Mining Sciences, 67, 78-87. http://dx.doi.org/10.1016/j.ijrmms.2014.01.011

[14] Raffaele, S., Cuccaro, A., Dell', A., et al. (2014) Ground Clutter Removal in GPR Surveys. IEEE Journal of Selected Topics in Applied Earth Observations and Remote Sensing, 7, 792-798. http://dx.doi.org/10.1109/JSTARS.2013.2287016

[15] Forte, E., Dossi, M., Colucci, R.R. and Pipan, M. (2013) A New Fast Methodology to Estimate the Density of Frozen Materials by Means of Common Offset GPR Data. Journal of Applied Geophysics, 99, 135-145. http://dx.doi.org/10.1016/j.jappgeo.2013.08.013

[16] Busch, S., Weihermüller, L., Huisman, J.A., et al. (2013) Coupled Hydrogeophysical Inversion of Time-Lapse Surface GPR Data to Estimate Hydraulic Properties of a Layered Subsurface. Water Resources Research, 49, 8480-8494. http://dx.doi.org/10.1002/2013WR013992 